\title{
Linearity Comparison of Three Colorimetric Cytotoxicity Assays
}

\author{
Maria Papadimitriou, Eleana Hatzidaki, Ioannis Papasotiriou* \\ Research Genetic Cancer Centre, Florina, Greece \\ Email: papadimitriou.maria@rgcc-genlab.com, hatzidaki.eleana@rgcc-genlab.com, ^office@rgcc-genlab.com
}

How to cite this paper: Papadimitriou, M., Hatzidaki, E. and Papasotiriou, I. (2019) Linearity Comparison of Three Colorimetric Cytotoxicity Assays. Journal of Cancer Therapy, 10, 580-590. https://doi.org/10.4236/jct.2019.107047

Received: June 11, 2019

Accepted: July 21, 2019

Published: July 24, 2019

Copyright $\odot 2019$ by author(s) and Scientific Research Publishing Inc. This work is licensed under the Creative Commons Attribution International License (CC BY 4.0).

http://creativecommons.org/licenses/by/4.0/ (c) (i) Open Access

\begin{abstract}
Cell viability assays, including techniques to assess the proliferation of cancer cell lines, constitute a rapid, inexpensive and sensitive screening method to pre-clinically evaluate the activity of a potential drug or substance. This study investigates and compares seeding densities and linearity of three such methods: MTT ((3-(4,5-dimethylthiazol-2-yl)-2,5-diphenyl tetrazolium bromide), SRB (sulforhodamine B) and CVE (crystal violet elution) assays. SRB and CVE are staining assays for proteins, while MTT measures the mitochondrial activity of living cells. Assays were performed on five cancer cell lines, A375, PC3, DU145, HCT116 and COR-L105, and the coefficient of determination (R2) was employed to determine fit into a linear regression model. The results show that CVE is the most linear assay at fixed time points. SRB at 515 $\mathrm{nm}$ is better for measurements over time. Seeding densities between 9000 and 12,000 were the optimum. However, seeding densities and doubling times should be taken into consideration when designing an experiment.
\end{abstract}

\section{Keywords}

Linearity, Cytotoxicity, Proliferation, Metabolism, Cancer

\section{Introduction}

Anti-cancer drug discovery is a longstanding goal of both researchers and pharmaceutical companies. Nevertheless, their activity evaluation is a laborious process that includes many steps. To this end, cell viability assays are the most common method used as a primary indicator of a given substance's cytotoxicity. Cytotoxicity assays are a valuable tool as they are rapid, inexpensive and sensitive techniques for pre-clinical assessment of a substance's anti-cancer activity.

The basis of these assays is the addition of a dye or chemical that induces a change of color that can subsequently be measured by the absorbance at a spe- 
cific wavelength. Several colorimetric assays have been used by researchers to measure metabolic activity or stain proteins. The linearity of measurements is an important issue, as it affects both the accuracy of results and sensitivity of the method [1]. Three colorimetric assays, (3-(4,5-dimethylthiazol-2-yl)-2,5-diphenyl tetrazolium bromide (MTT), sulforhodamine B (SRB) and crystal violet elution (CVE), were investigated for their linearity in the current study. The MTT assay measures metabolic activity, while SRB and CVE are protein-staining assays.

Tim Mosmann developed an assay measuring the reduction of MTT in 1983. Normally a pale yellow substance, MTT produces dark blue formazan crystals when incubated with living cells. The generation of formazan crystals correlates with the mitochondrial activity of the cell, suggesting that MTT specifically measures living cells [2] [3].

The CVE method has been used for various applications (reviewed by Vega-Avila et al., 2011) [4]. Crystal violet is a dye that binds both to proteins and DNA. Non-viable cells lose their ability to adhere to the surface of cell culture plates, resulting in less dye uptake [5]. The CVE assay represents a quick method to determine cell proliferation.

Introduced by Philip Skehan in 1990 [6], the SRB assay is based on uptake and binding of a bright pink dye by basic amino acids under acidic conditions, which subsequently dissociate under basic conditions [7]. Presently, the SRB assay is used by the National Cancer Institute (NCI) for drug-toxicity testing of a panel of 60 cell lines.

The advantage of these assays arises from the fact that they measure different parts of the cell, namely protein content and metabolic activity. Moreover, since they are in-house protocols, there is an opportunity for optimization via dye or chemical concentration adaptation; this feature is not possible with use of commercial cytotoxicity kits. Last but not least, compared with alternative methods of cell tracking that require expensive equipment and/or reagents, the low cost of MTT, SRB and CVE makes these methods affordable for laboratories around the world.

The aim of this paper is to assess linearity of each method 1) using different cell concentrations at a given time point. In this way we evaluated the optimum cell seeding density after 24,48 or 72 hours of culture but also linearity of the methods at the given, fixed time points. Fixed time points reflect different cell numbers and depend on cell's doubling times and 2) since usually a compound's cytotoxicity is tested over a time period of up to $72 \mathrm{hr}$ of incubation, we evaluated linearity of these methods over time using constant cell seeding densities.

\section{Materials and Methods}

\subsection{Cell Culture}

Five cell lines obtained from ECACC and ATCC were used to conduct colorimetric assays. Table 1 summarizes the media and appropriate supplements used for their culture in T-75 flasks (0030711122, Eppendorf). Cells in logarithmic 
Table 1. Cell line suppliers and culture media.

\begin{tabular}{|c|c|c|c|}
\hline CELL LINE & SUPPLIED BY & CAT. NO. & MEDIA AND SUPPLEMENTS \\
\hline HCT116 & ECACC & 91091005 & $\mathrm{DMEM}^{1}+10 \% \mathrm{FBS}^{2}+2 \mathrm{mM} \mathrm{L-Glutamine}{ }^{3}$ \\
\hline COR-L105 & ECACC & CORL105 & RPMI- $1640^{4}+10 \%$ FBS $+2 \mathrm{mM}$ L-Glutamine \\
\hline DU145 & ATCC & $\mathrm{ATCC}^{\circledR} \mathrm{HTB} 81^{\mathrm{TM}}$ & $\mathrm{EMEM}^{5}+10 \% \mathrm{FBS}$ \\
\hline PC3 & ECACC & 90112714 & DMEM+10\% FBS + 2 mM L-Glutamine \\
\hline A375 & ECACC & 88113005 & DMEM + 15\% FBS + 2 mM L-Glutamine \\
\hline
\end{tabular}

1 = D5546, Sigma 2 = FB-1001/500, BioSera 3 = G7513, Sigma 4 = R0883, Sigma 5 = 30-2003, ATCC.

growth phase were detached by trypsinization and plated in 96-well plates (4430100, Orange Scientific) at various densities (3000, 9000, 12,000, 18,000 and 21,000 cells per well) in a final volume of $200 \mu \mathrm{l}$ per well.

These five cell lines were chosen because of their different recommended subculture ratios. Specifically, HCT116 and A375 cell lines are fast-growing according to their recommended subcultivation ratios, $1: 3-1: 10$ and 1:3 - 1:8, respectively. Whereas, PC3 and COR-L105 have similar subculture ratios, 1:2 - 1:6 and 1:3 - 1:6, respectively, and DU145 has a recommended subcultivation ratio of 1:4 - 1:6. Also, according to their doubling times, A375 is the fastest growing $(18 \mathrm{hr})$ and COR-L105 is the slowest growing $(40 \mathrm{hr})$ cell line with all the others being in between. As far as their characteristics are concerned, HCT116 is a human colon carcinoma cell line; A375 is a human malignant melanoma cell line; PC3 is a human Caucasian prostate adenocarcinoma cell line; COR-L105 is a human Caucasian lung adenocarcinoma cell line; DU145 is a prostate, derived from metastatic site in the brain cell line.

\subsection{Viability Assays}

All three viability assays (MTT, CVE, SRB) are colorimetric. As such, cell proliferation can be quantified by measuring the optical density of assay products at various wavelengths. Optical density measurements were conducted using a $\mu$ Quant $^{\mathrm{TM}}$ Biomolecular Spectrophotometer MQX200 and analysis with Gen5 $5^{\mathrm{TM}}$ Microplate Data Collection \& Analysis software (BioTek ${ }^{\circledR}$ Instruments, April 2008, @2006-2008, Revision E).

Absorbance values were measured in triplicate at 3 different time points (24, 48 , and 72 hours post-plating). A triplet without cells served as blank control, whereby assays were performed as described below, and it was subsequently redacted from the average absorbance values of tested samples. MTT and CVE protocols were based on methods described in "Essential Cell Biology, Vol. 1 Cell Structure, A Practical Approach" (2003) [8]. The SRB protocol was based on the method described by Vichai et al. [9].

\section{MTT assay}

For the MTT assay, $20 \mu \mathrm{l}$ of MTT ( $5 \mathrm{mg} / \mathrm{ml}$; M2128, Sigma) was added directly into culture medium in each well. Cells were then incubated for 3 hours at $37^{\circ} \mathrm{C}$ and $5 \% \mathrm{CO}_{2}$. Subsequently, the supernatant was removed and cells were 
washed with $100 \mu \mathrm{l}$ of $0.01 \mathrm{M}$ phosphate-buffered saline solution (PBS; P3813, Sigma). Formazan crystals that formed were solubilized with $100 \mu \mathrm{l}$ of DMSO (445103, Carlo Erbo Reagents). The absorbance was measured at $570 \mathrm{~nm}$ and $630 \mathrm{~nm}$ to subtract background noise.

CVE assay

For CVE assay, the culture medium was removed and cells were rinsed with $100 \mu \mathrm{l}$ of PBS. Subsequently, cells were fixed by adding $100 \mu \mathrm{l}$ of $10 \%$ formalin for 10 minutes. Formalin was decanted and the plates were allowed to air dry. Next, $100 \mu \mathrm{l}$ of $0.25 \%$ aqueous crystal violet solution (HT901, Sigma) was added to each well for 10 minutes. The supernatant was decanted and plates were washed four times with $100 \mu \mathrm{l}$ of water for injection (WFI) and allowed to dry. Solubilization was achieved by adding $100 \mu \mathrm{l}$ of $33 \%$ glacial acetic acid. Optical density was measured at $570 \mathrm{~nm}$ and corrected at $690 \mathrm{~nm}$.

SRB assay

For SRB assay, cells were fixed by adding $100 \mu \mathrm{l}$ of $10 \%$ trichloroacetic acid (TCA; 91228, Sigma) directly to the cell culture plate and incubating cells at $4^{\circ} \mathrm{C}$ for 1 hour. Thereafter, the supernatant was removed, cells were rinsed twice with $100 \mu \mathrm{l}$ of WFI to remove TCA, and plates were allowed to air dry. Next, $100 \mu \mathrm{l}$ of SRB solution ( $0.4 \%$ in $1 \%$ glacial acetic acid; 341738 , Sigma) was added to each well and plates were incubated at room temperature for 30 minutes. After incubation, cells were rinsed four times with $100 \mu \mathrm{l}$ of $1 \%$ glacial acetic acid (1.00063.1011, Merck) to remove unbound dye and the plates were allowed to dry. The dye was solubilized by adding $200 \mu \mathrm{l}$ of 10 mMTris-base pH 10.5 (T6791, Sigma). Absorbance was measured at 570 and $515 \mathrm{~nm}$, and then corrected at $690 \mathrm{~nm}$.

\subsection{Statistical Analysis}

The average absorbance was calculated for each triplet. Subsequently, the sample measurements were corrected for the measurement of the blank. Moreover, in order to determine whether results fit into a linear regression model, the coefficient of determination (R2) was calculated among the average measurements of the initial seeded cells at three different time points $(24,48$ and 72 hours post-plating). Results are represented as R2 (Standard Error) where R2 is an indicator of the goodness of fit and Standard Error shows the precision of the regression analysis. All results were calculated using the Regression tool in Excel ${ }^{\mathrm{TM}}$ 2016 (Microsoft Office $^{\circledR}$ ).

\section{Results}

Linearity was studied among the three assays and also between the two wavelengths used in the SRB assay, for which optical density measured at $515 \mathrm{~nm}$ has been suggested to be more linear [9]. Cell concentrations yielding more linear results were also investigated for each assay at specific time points, as well as linearity over time.

In the CVE assay, A375, DU145 and PC3 exhibited very good linearity be- 
tween the seeding densities studied in all time points. COR-L105 linearity was somewhat lower and HCT116 exhibited good linearity at $24 \mathrm{hr}$ (Table 2(a)). When studying linearity over time, coefficient of determination (R2) value above 0.9 exhibited all cell lines when seeded between 9000 and 12,000 cells per well, except from COR-L105 which had better linearity at 18,000 cells. In contrast, when 3000 cells were seeded per well, R2 values exceeded 0.9 in three out of five cell lines (Table 2(b)). Consequently, most of seeding densities produce linear results, but seeding densities between 9000 and 12,000 cells resulted in more linear data. COR-L105 linearity was lower at conditions with less seeding densities, such as $24 \mathrm{hr}$ and $48 \mathrm{hr}$, as well as in 3000 cells/well.

The MTT assay presented variable results that did not follow any pattern. R2 values were lower at $24 \mathrm{hr}$ and HCT116 was the most problematic cell line of the 5 (Table 3(a)). Similarly, over time most of the R2 values varied greatly. Again, HCT116 had the worst linearity but overall 18,000 cells gave the best results (Table 3(b)).

The SRB assay was measured at two different wavelengths, 515 and $570 \mathrm{~nm}$, to compare ensuing linearity motifs. Linearity of the method was better at $515 \mathrm{~nm}$ as far as seeding densities at fixed time points was concerned (Table 4(a)). 570 $\mathrm{nm}$ linearity was better at $24 \mathrm{hr}$ and seemed to be reduced at $72 \mathrm{hr}$, (Table 5(a)). When studying linearity over time, at almost every cell concentration examined, all cell lines presented a slightly more linear pattern at $515 \mathrm{~nm}$ than at $570 \mathrm{~nm}$, especially between 3000 - 12,000 cells (Table 4(b)). With regard to the linearity motifs present at $570 \mathrm{~nm}$, all five cell lines appeared to have a linear relation to optical density when seeded with 9000 and 12,000 cells per well. However, this

Table 2. (a) CVE linearity at fixed time points (24, 48 and $72 \mathrm{hr})$ using different seeding densities; (b) CVE linearity at fixed cell concentration (3000, 9000, 12,000, 18,000 and 21,000 cells/well) during 24,48 and $72 \mathrm{hr}$ of consecutive incubations.

(a)

\begin{tabular}{cccccc}
\hline \multicolumn{5}{c}{ R2 coefficient variation CVE assay (Standard Error) } \\
\hline Time Points & A375 & COR-L105 & DU145 & HCT116 & PC3 \\
\hline $24 \mathrm{hr}$ & $0.98(0.03)$ & $0.75(0.02)$ & $0.98(0.01)$ & $0.99(0.03)$ & $0.99(0.006)$ \\
$48 \mathrm{hr}$ & $0.99(0.02)$ & $0.65(0.03)$ & $0.99(0.01)$ & $0.03(0.6)$ & $0.98(0.04)$ \\
$72 \mathrm{hr}$ & $0.94(0.07)$ & $0.8(0.05)$ & $0.93(0.1)$ & $0.17(0.3)$ & $0.94(0.12)$ \\
\hline
\end{tabular}

(b)

\begin{tabular}{cccccc}
\hline \multicolumn{7}{c}{ R2 coefficient variation CVE assay (Standard Error) } \\
\hline \multirow{2}{*}{ Seeded cells } & A375 & COR-L105 & DU145 & HCT116 & PC3 \\
\hline 3000 & $0.99(0.01)$ & $0.68(0.005)$ & $0.84(0.02)$ & $0.97(0.1)$ & $0.94(0.01)$ \\
9000 & $0.97(0.09)$ & $0.87(0.009)$ & $0.95(0.05)$ & $0.99(0.006)$ & $0.99(0.01)$ \\
12,000 & $0.90(0.18)$ & $0.89(0.02)$ & $0.96(0.05)$ & $0.95(0.17)$ & $0.97(0.07)$ \\
18,000 & $0.94(0.15)$ & $0.93(0.02)$ & $0.95(0.09)$ & $0.35(0.68)$ & $0.98(0.09)$ \\
21,000 & $0.84(0.24)$ & $0.65(0.08)$ & $0.87(0.2)$ & $0.99(0.06)$ & $0.98(0.07)$ \\
\hline
\end{tabular}


Table 3. (a) MTT linearity at fixed time points (24, 48 and $72 \mathrm{hr}$ ) using different seeding densities; (b) MTT linearity at fixed cell concentration (3000, 9000, 12,000, 18,000 and 21,000 cells/well) during 24,48 and $72 \mathrm{hr}$ of consecutive incubations.

(a)

\begin{tabular}{cccccc}
\hline \multicolumn{5}{c}{ R2 coefficient variation MTT assay (Standard Error) } \\
\hline Time Points & A375 & COR-L105 & DU145 & HCT116 & PC3 \\
\hline $24 \mathrm{hr}$ & $0.55(0.02)$ & $0.78(0.01)$ & $0.221(0.03)$ & $0.42(0.09)$ & $0.6(0.06)$ \\
$48 \mathrm{hr}$ & $0.99(0.002)$ & $0.78(0.02)$ & $0.94(0.006)$ & $0.24(0.14)$ & $0.8(0.16)$ \\
$72 \mathrm{hr}$ & $0.56(0.11)$ & $0.94(0.01)$ & $0.99(0.004)$ & $0.36(0.22)$ & $0.95(0.05)$ \\
\hline
\end{tabular}

(b)

\begin{tabular}{cccccc}
\hline \multicolumn{5}{c}{ R2 coefficient variation MTT assay (Standard Error) } \\
\hline Seeded cells & A375 & COR-L105 & DU145 & HCT116 & PC3 \\
\hline 3000 & $0.91(0.13)$ & $0.75(0.001)$ & $0.99(0.002)$ & $0.78(0.17)$ & $0.88(0.05)$ \\
9000 & $0.83(0.14)$ & $0.88(0.006)$ & $0.94(0.06)$ & $0.26(0.62)$ & $0.82(0.16)$ \\
12,000 & $0.85(0.18)$ & $0.62(0.02)$ & $0.92(0.08)$ & $0.03(0.65)$ & $0.85(0.19)$ \\
18,000 & $0.96(0.07)$ & $0.88(0.015)$ & $0.94(0.09)$ & $0.15(0.82)$ & $0.95(0.12)$ \\
21,000 & $0.9(0.17)$ & $0.81(0.02)$ & $0.88(0.14)$ & $0.43(0.46)$ & $0.91(0.16)$ \\
\hline
\end{tabular}

Table 4. (a) SRB $515 \mathrm{~nm}$ linearity at fixed time points (24, 48 and $72 \mathrm{hr})$ using different seeding densities; (b) SRB $515 \mathrm{~nm}$ linearity at fixed cell concentration $(3000,9000,12,000$, 18,000 and 21,000 cells/well) during 24, 48 and $72 \mathrm{hr}$ of consecutive incubations.

(a)

\begin{tabular}{cccccc}
\hline \multicolumn{5}{c}{ R2 coefficient variation SRB } & \multicolumn{4}{c}{ nm assay (Standard Error) } & \\
\hline \multirow{2}{*}{ Time Points } & A375 & COR-L105 & DU145 & HCT116 & PC3 \\
\hline $24 \mathrm{hr}$ & $0.98(0.03)$ & $0.75(0.03)$ & $0.97(0.02)$ & $0.97(0.07)$ & $0.92(0.06)$ \\
$48 \mathrm{hr}$ & $0.95(0.19)$ & $0.74(0.07)$ & $0.96(0.06)$ & $0.88(0.24)$ & $0.99(0.02)$ \\
$72 \mathrm{hr}$ & $0.95(0.04)$ & $0.61(0.1)$ & $0.99(0.01)$ & $0.97(0.05)$ & $0.96(0.11)$ \\
\hline
\end{tabular}

(b)

\begin{tabular}{cccccc}
\hline \multicolumn{5}{c}{ R2 coefficient variation SRB $515 \mathrm{~nm}$ assay (Standard Error) } \\
\hline Seeded cells & A375 & COR-L105 & DU145 & HCT116 & PC3 \\
\hline 3000 & $0.98(0.04)$ & $0(0)$ & $0.93(0.03)$ & $0.98(0.06)$ & $0.95(0.01)$ \\
9000 & $0.94(0.27)$ & $0.99(0.007)$ & $0.99(0.008)$ & $0.99(0.09)$ & $0.98(0.017)$ \\
12,000 & $0.96(0.21)$ & $0.99(0.0008)$ & $0.99(0.018)$ & $0.98(0.13)$ & $0.97(0.07)$ \\
18,000 & $0.73(0.6)$ & $0.99(0.003)$ & $0.98(0.09)$ & $0.90(0.39)$ & $0.99(0.07)$ \\
21,000 & $0.76(0.5)$ & $0.90(0.04)$ & $0.99(0.01)$ & $0.92(0.31)$ & $0.99(0.01)$ \\
\hline
\end{tabular}

was not the case for higher cell densities above 18,000 cells per well. Moreover, COR-L105 linearity at 3000 was zero due to the fact that absorbance values were too low due to the cell growth rate (Table 5(b)).

Linearity was also compared among the assays for all cell lines studied. In par- 
ticular, comparisons among the three colorimetric methods revealed that CVE gave the most linear results at fixed time points when using the particular seeding densities. However, over time SRB gave the most linear results and particularly between 9000 and 12,000 cells. In contrast, the MTT assay was the least linear, as no repeatable patterns were observed for any of the cell concentrations examined.

All the results are summed up is Table 6.

Table 5. (a) SRB $570 \mathrm{~nm}$ linearity at fixed time points $(24,48$ and $72 \mathrm{hr}$ ) using different seeding densities; (b) SRB $570 \mathrm{~nm}$ linearity at fixed cell concentration (3000, 9000, 12,000, 18,000 and 21,000 cells/well) during 24, 48 and $72 \mathrm{hr}$ of consecutive incubations.

(a)

\begin{tabular}{cccccc}
\hline \multicolumn{5}{c}{ R2 coefficient variation SRB 570} & nm assay (Standard Error) \\
\hline Time Points & A375 & COR-L105 & DU145 & HCT116 & PC3 \\
\hline $24 \mathrm{hr}$ & $0.99(0.05)$ & $0.76(0.09)$ & $0.98(0.05)$ & $0.98(0.09)$ & $0.94(0.13)$ \\
$48 \mathrm{hr}$ & $0.75(0.26)$ & $0.73(0.19)$ & $0.96(0.12)$ & $0.63(0.13)$ & $0.99(0.04)$ \\
$72 \mathrm{hr}$ & $0.67(0.03)$ & $0.61(0.27)$ & $0.93(0.18)$ & $0.96(0.01)$ & $0.88(0.19)$ \\
\hline
\end{tabular}

(b)

\begin{tabular}{cccccc}
\hline \multicolumn{5}{c}{ R2 coefficient variation SRB } & 570 nm assay (Standard Error) \\
\hline Seeded cells & A375 & COR-L105 & DU145 & HCT116 & PC3 \\
\hline 3000 & $0.99(0.08)$ & $0(0)$ & $0.93(0.08)$ & $0.99(0.1)$ & $0.97(0.03)$ \\
9000 & $0.99(0.07)$ & $0.99(0.004)$ & $0.99(0.003)$ & $0.82(0.49)$ & $0.98(0.08)$ \\
12,000 & $0.83(0.49)$ & $0.99(0.03)$ & $0.98(0.12)$ & $0.93(0.26)$ & $0.99(0.07)$ \\
18,000 & $0.73(0.41)$ & $0.99(0.02)$ & $0.99(0.039)$ & $0.80(0.2)$ & $0.96(0.21)$ \\
21,000 & $0.76(0.24)$ & $0.89(0.13)$ & $0.93(0.27)$ & $0.86(0.1)$ & $0.92(0.23)$ \\
\hline
\end{tabular}

Table 6. A comparison of all three assays and all parameters.

\begin{tabular}{|c|c|c|c|c|}
\hline & MTT & SRB $(515 \mathrm{~nm})$ & SRB $(570 \mathrm{~nm})$ & CVE \\
\hline 3000 A375 cells & $0.91(0.13)$ & $0.98(0.04)$ & $0.99(0.08)$ & $0.99(0.01)$ \\
\hline 9000 A375 cells & $0.83(0.14)$ & $0.94(0.27)$ & $0.99(0.07)$ & $0.97(0.09)$ \\
\hline 12,000 A375 cells & $0.85(0.18)$ & $0.96(0.21)$ & $0.83(0.49)$ & $0.90(0.18)$ \\
\hline 18,000 A375 cells & $0.96(0.07)$ & $0.73(0.6)$ & $0.73(0.41)$ & $0.94(0.15)$ \\
\hline 21,000 A375 cells & $0.9(0.17)$ & $0.76(0.5)$ & $0.76(0.24)$ & $0.84(0.24)$ \\
\hline $24 \mathrm{hr}$ A375 cells & $0.55(0.02)$ & $0.98(0.03)$ & $0.99(0.05)$ & $0.98(0.03)$ \\
\hline $48 \mathrm{hr}$ A375 cells & $0.99(0.002)$ & $0.95(0.19)$ & $0.75(0.26)$ & $0.99(0.02)$ \\
\hline $72 \mathrm{hr}$ A375 cells & $0.56(0.11)$ & $0.95(0.04)$ & $0.67(0.03)$ & $0.94(0.07)$ \\
\hline 3000 COR-L105 cells & $0.75(0.001)$ & $0(0)$ & $0(0)$ & $0.68(0.005)$ \\
\hline 9000 COR-L105 cells & $0.88(0.006)$ & $0.99(0.007)$ & $0.99(0.004)$ & $0.87(0.009)$ \\
\hline 12,000 COR-L105 cells & $0.62(0.02)$ & $0.99(0.0008)$ & $0.99(0.03)$ & $0.89(0.02)$ \\
\hline 18,000 COR-L105 cells & $0.88(0.015)$ & $0.99(0.003)$ & $0.99(0.02)$ & $0.93(0.02)$ \\
\hline
\end{tabular}




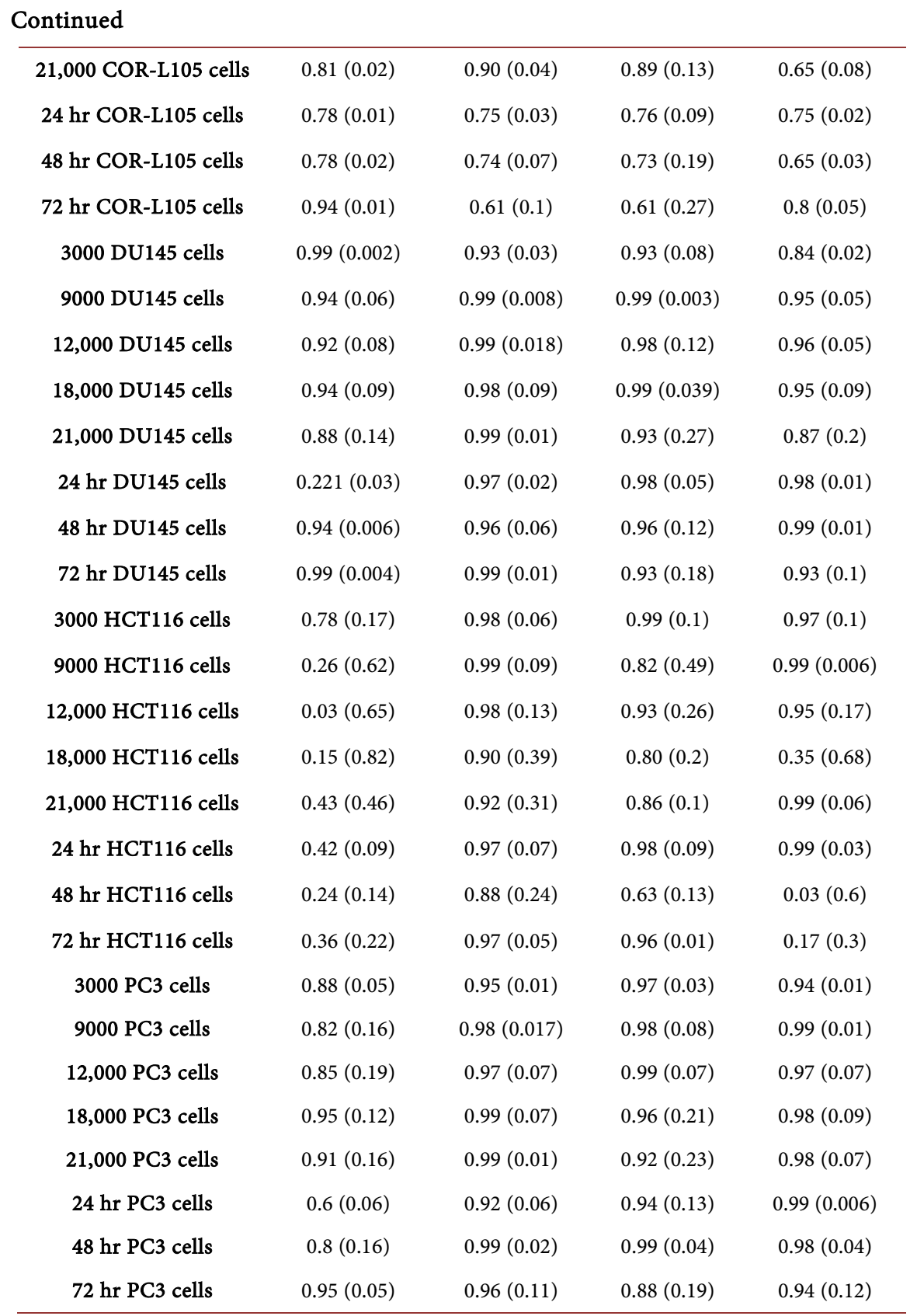

\section{Discussion}

The present study investigated the linear profile of three colorimetric cytotoxicity assays (MTT, SRB and CVE), as well as the cell seeding density producing the most linear data both on fixed time points or over time observations. It should be stated here that fixed time points reflect cell numbers. For example, the fastest growing line (A375; $18 \mathrm{hr}$ doubling time) will start with 3000, 9000, 12,000, 18,000 and 21,000 cells at $0 \mathrm{hr}$ and go to 45,000,13,500,18,000, 27,000 and 315,000 at $24 \mathrm{hr}$. Whereas the slowest growing line (COR-L105; $40 \mathrm{hr}$ doubling time) will have almost the same cell number at 24 and $48 \mathrm{hr}$ and double cell numbers at $72 \mathrm{hr}$. Even though the techniques described here were developed 
almost 25 years ago, they continue to be regularly used by researchers to determine the cytotoxicity of various substances [10] [11] [12].

Multiple studies have investigated the advantages and disadvantages of these assays, and have compared them to each other, as reviewed by Vega-Avila et al. [4]. The MTT assay, which is the most common of the three assays presented here according to international literature, seems to have the least linear relation between optical density and cell number [13]. This is in accordance with results of the present study, showing the MTT assay is the least linear both as far as the seeding densities are concerned as well as incubations over time. This difference in linearity among cell lines could result from the different dehydrogonase activity (required for the production of formazan crystals) of each cell line's mitochondria [14]. Moreover, Liu et al. [15] suggested that the rate of formazan exocytosis plays an important role in cellular MTT reduction, as formazan crystals covering the cell's surface inhibit MTT uptake. Furthermore, Liu suggested that different cell types possess different formazan exocytosis rates, as different factors affect exocytosis in each cell line. To minimize the effect of various conditions on assay results, Vistica et al. [16] suggested that seeding density conditions should be established for every cell line prior to assay performance. Therefore, the MTT assay seems to be the least linear assay of the three examined and every cell line should be characterized for its linearity before performing an MTT assay.

The CVE assay is also a simple method for assessing cytotoxicity. In the present study, it was found that the best linearity results were achieved at $24 \mathrm{hr}$ and $48 \mathrm{hr}$ of incubation. Over time, best linearity was found when the initial cell concentration was between 9000 and 12,000 cells per well. COR-L105 linearity improved at $72 \mathrm{hr}$. This could probably be due to the slower growth rate of the particular cell line. Nevertheless, according to Chiba et al. [14], absorbance measurements are affected by the uniformity of cells on the bottom of the well. This study, however, has proven that the CVE assay has a linear relation between optical density and cell concentration in multiple cell lines.

This study also compared linearity between measurements at two wavelengths, 515 and $570 \mathrm{~nm}$, for the SRB assay. Results obtained from five cell lines revealed that linearity is better at $515 \mathrm{~nm}$. Seeding densities between 9000 and 12,000 cells per well produced coefficients of determination above 0.9 for all cell lines, indicating that the SRB assay also requires a cell density of 9000 to 12,000 cells in order to achieve the most linear results possible.

\section{Conclusion}

In conclusion, among the three assays presently studied, CVE was the most linear at fixed time points. However, when studying the cytotoxic nature of a compound it is usual to evaluate the effect over time. In this case, SRB gives better linearity, especially at $515 \mathrm{~nm}$ and between 9000 - 12,000 cells. These findings are supported by previous studies [13] that showed that the SRB assay had better 
linearity than MTT. Therefore, every cell line has unique characteristics and, to obtain accurate results, should be characterized before proceeding to cytotoxicity assays. Our results demonstrate that doubling times have a profound effect in linearity of every method and have to be taken into account during the design of the experiment. Nevertheless, the aforementioned viability assays constitute a valuable tool to cancer research, as, independently of their linearity, they are able to screen a wide spectrum of the cell's content and activities, including both protein content and metabolic activity.

\section{Conflicts of Interest}

The authors report no conflicts of interest; Source of funding none declared.

\section{References}

[1] Posimo, J.M., Unnithan, A.S., Gleixner, A.M., Choi, H.J., Jiang, Y., Pulugulla, S.H. and Leak, R.K. (2014) Viability Assays for Cells in Culture. Journal of Visualized Experiments, 83, e50645. https://doi.org/10.3791/50645

[2] Berridge, M.V. and Tan, A.S. (1993) Characterization of the Cellular Reduction of 3-(4,5-dimethylthiazol-2-yl)-2,5-diphenyltetrazolium Bromide (MTT): Subcellular Localization, Substrate Dependence, and Involvement of Mitochondrial Electron Transport in MTT Reduction. Arch BiochemBiophys, 303, 474-482. https://doi.org/10.1006/abbi.1993.1311

[3] Mosmann, T. (1983) Rapid Colorimetric Assay for Cellular Growth and Survival: Application to Proliferation and Cytotoxicity Assays. Journal of Immunological Methods, 65, 55-63. https://doi.org/10.1016/0022-1759(83)90303-4

[4] Vega-Avila, E. and Pugsley, M.K. (2011) An Overview of Colorimetric Assay Methods Used to Assess Survival or Proliferation of Mammalian Cells. Proceedings of the Western Pharmacology Society, 54, 10-14.

[5] Feoktistova, M., Geserick, P. and Leverkus, M. (2016) Crystal Violet Assay for Determining Viability of Cultured Cells. Cold Spring Harbor Protocols, 2016, pdb.prot087379. https://doi.org/10.1101/pdb.prot087379

[6] Skehan, P., Storeng, R., Scudiero, D., Monks, A., McMahon, J., Vistica, D., Warren, J.T., Bokesch, H., Kenney, S. and Boyd, M.R. (1990) New Colorimetric Cytotoxicity Assay for Anti-Cancer-Drug Screening. Journal of the National Cancer Institute, 82, 1107-1112. https://doi.org/10.1093/jnci/82.13.1107

[7] McCaffrey, T.A., Agarwal, L.A. and Weksler, B.B. (1988) A Rapid Fluorometric DNA Assay for the Measurement of Cell Density and Proliferation in Vitro. In Vitro Cellular \& Developmental Biology, 24, 247-252. https://doi.org/10.1007/BF02623555

[8] Touhey, S. and Heenan, M. (2003) Cell Culture. In: Davey, J. and Lord, M., Eds., Essential Cell Biology, Vol. 1 Cell Structure, a Practical Approach, Oxford University Press, Oxford, 28-31.

[9] Vichai, V. and Kirtikara, K. (2006) Sulforhodamine B Colorimetric Assay for Cytotoxicity Screening. Nature Protocols, 1, 1112-1116. https://doi.org/10.1038/nprot.2006.179

[10] Seo, J.A., Kim, B., Dhanasekaran, D.N., Tsang, B.K. and Song, Y.S. (2016) Curcumin Induces Apoptosis by Inhibiting Sarco/Endoplasmic Reticulum $\mathrm{Ca}^{2+}$ ATPase Activity in Ovarian Cancer Cells. Cancer Letters, 371, 30-37. 
https://doi.org/10.1016/j.canlet.2015.11.021

[11] Johnson-Ajinwo, O.R., Richardson, A. and Li, W.W. (2015) Cytotoxic Effects of Stem Bark Extracts and Pure Compounds from Margaritaria Discoidea on Human Ovarian Cancer Cell Lines. Phytomedicine, 22, 1-4. https://doi.org/10.1016/j.phymed.2014.09.008

[12] Martins, C.A., Leyhausen, G., Volk, J. and Geurtsen, W. (2015) Effects of Alendronate on Osteoclast Formation and Activity in Vitro. Journal of Endodontics, 41, 45-49. https://doi.org/10.1016/j.joen.2014.07.010

[13] Keepers, Y.P., Pizao, P.E., Peters, G.J., van Ark-Otte, J., Winograd, B. and Pinedo, H.M. (1991) Comparison of the Sulforhodamine B Protein and Tetrazolium (MTT) Assays for in Vitro Chemosensitivity Testing. European Journal of Cancer, 27, 897-900. https://doi.org/10.1016/0277-5379(91)90142-Z

[14] Chiba, K., Kawakami, K. and Tohyama, K. (1998) Simultaneous Evaluation of Cell Viability by Neutral Red, MTT and Crystal Violet Staining Assays of the Same Cells. Toxicology in Vitro, 12, 251-258. https://doi.org/10.1016/S0887-2333(97)00107-0

[15] Liu, Y., Peterson, D.A., Kimura, H. and Schubert, D. (1997) Mechanism of Cellular 3-(4,5-dimethylthiazol-2-yl)-2,5-diphenyltetrazolium Bromide (MTT) Reduction. Journal of Neurochemistry, 69, 581-593.

https://doi.org/10.1046/j.1471-4159.1997.69020581.x

[16] Vistica, D.T., Skehan, P., Scudiero, D., Monks, A., Pittman, A. and Boyd, M.R. (1991) Tetrazolium-Based Assays for Cellular Viability: A Critical Examination of Selected Parameters Affecting Formazan Production. Cancer Research, 51, 2515-2520. 